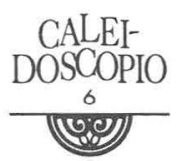

JULOODICIEMBRE 1999

\title{
La Virgen de Guadalupe en Zacatecas: una imagen en pugna ${ }^{1}$
}

MARIANA TERÁN FUENTES

Facultad de Humanidades/UNIVERSIDAD AUTÓNOMA DE ZACATECAS

a Virgen de Guadalupe ha sido para México uno de los más importantes símbolos de identidad nacional. Guadalupe es un elemento simbólico que ayuda a entender el contexto histórico fundacional del país. Su aparición en el Tepeyac a Juan Diego y la plasmación de su imagen en una tosca tela en medio de un lugar agreste, marcaron un hito en la cultura religiosa mexicana. La bibliografía en torno a Guadalupe no sólo es rica en extensión, sino en su variedad: ${ }^{2}$ desde la iconografía y la historia del arte; desde la sociología y el fenómeno de la religiosidad popular; desde la antropología y las formas simbólicas que representa culturalmente; desde la política como la recuperación de una imagen de identidad y nación; hasta la historia cultural como un complejo mundo de representa-

1 Este artículo forma parte de una investigación mayor titulada El artificio de la fe. Elites y sermones en Zacatecas durante el siglo Xilli.

2 Es imposible hacer referencia mínima a los textos guadalupanos, sin embargo mencionamos, por lo menos, de Jaques Lafaye, Quetzalcóatl y Guadalupe, México, FCE; Serge Gruzinski La guerra de las imágenes, México, FCE, 1994; de Francisco de Florencia y Juan Antonio de Oviedo, con introducción de Antonio Rubial, El zodiaco mariano, México, CNCA, 1995; de Francisco de la Maza, El guadalupanismo mexicano, México, FCE, Lecturas mexicanas 37, 1992; de Ignacio Osorio Romero, El sueño criollo, México, Unam, 1991; de Richard Nebel, Santa María Tonantzin Virgen de Guadalupe, México, FCE, 1995. 
ciones y de construcción del imaginario social. Pero también Guadalupe a través de imágenes, retablos, templos; Guadalupe en graffitis, canciones, leyendas y la formación de nuevos relatos.

Para el período novohispano, la formación cultual en torno a Guadalupe implicó en sí misma la formación de una realidad social; su explicación, basada en el relato de las apariciones en el Tepeyac, se nutrió de controversias entre aparicionistas y antiaparicionistas. El milagro guadalupano no consistió únicamente en el relato aparicionista, sino en la importancia significativa de trascender para generar una identidad. Sin embargo, mucho se ha hablado de Guadalupe en la formación de la identidad mexicana y poco se ha dicho sobre el significado que tuvo la Virgen Morena para otros grupos sociales que también querían apoyarse en ella para formar su propia identidad.

Hay toda una tradición historiográfica y religiosa heredada desde el centro de la Nueva España: la Virgen de Guadalupe protectora de sus hijos contra epidemias como la del matlazáhuatl en 1737 , Guadalupe como intercesora para que las sequías no provocaran más enfermedades y muertes, Guadalupe como madre para no dejar sin su abogacía a sus hijos. Pero también Guadalupe en contraposición con otras advocaciones marianas, como el culto principal, el culto central, el culto que identificaba regiones, las unía, y por qué no, como el culto oficial.

Sin embargo, los significados de ese relato central y oficial no fueron los mismos para todas las regiones, es decir, las apropiaciones del culto guadalupano tuvieron que ver con una relación a veces forzada y tensa entre los motivos emitidos desde el centro para ofrecer el culto a la Virgen y los motivos locales para reverenciarla. Bajo esta línea, nos preguntamos qué pasó en la muy Noble y Leal Ciudad de Zacatecas hacia el siglo XVIII en torno a Guadalupe; entre quiénes se fue definiendo la frontera del culto y qué identidades y conflictos de poder intervinieron en esa definición. 
La IMAGen MÁs CLARa de LO MÁs OCULTo de María.

EL CULTO GUADALUPANO A EXTRAMUROS

Hacia 1686 llegaron a Zacatecas los frailes Francisco Estévez, Antonio Escaray y Francisco Hidalgo "para que fructificara la semilla de la palabra divina." Según Alcocer en su Historia del Colegio de Guadalupe, los misioneros se quedaron asombrados por la piedad de los mineros zacatecanos, quienes otorgaban dádivas para la construcción de templos o pagaban los derechos parroquiales para que todos los que mal vivían se casaran. ${ }^{3}$ Fue justo con este tipo de donaciones que en la ermita dedicada a Nuestra Señora del Carmen se erigió una capilla y después un hospicio para los misioneros. Se otorgó licencia por el cabildo en sede vacante de Guadalajara el 9 de septiembre de 1702 para la fundación de un hospicio en el Santuario de Nuestra Señora de Guadalupe de Zacatecas ${ }^{4}$ y para 1707, dada la aprobación en real cédula, se constituyó el Colegio Apostólico, siendo su fundador fray Antonio Margil de Jesús:

Determinó que todos los individuos de esta comunidad, entonces y en lo porvenir, siempre la habían de reconocer por Prelada; y él y demás prelados que el Colegio tuviere, como unos meros ejecutores de la soberana voluntad de la Virgen Madre. Por esta causa desde aquel tiempo hasta hoy, cuando ocurre nombrar a la Santísima Virgen de Guadalupe, lo hacemos con estas palabras (y jamás con otras) Nuestra Santísima PreLada. ${ }^{5}$

La fundación del Colegio y su advocación guadalupana fue constantemente enriquecida por la predicación de sus frailes. La tradición de Guadalupe en Zacatecas puede explicarse también a partir de los relatos que los prelados realizaron. A principios del siglo

3 José Antonio Alcocer, Bosquejo de la historia del Colegio de Guadalupe y sus misiones, México, Porrúa, 1958, p. 62.

4. Ibid., p. 65.

5 Ibid., p. 70; véase lo referente a la fundación del Colegio de Guadalupe en Isidro Félix de Espinosa, Crónica de los Colegios de propaganda Fide de la Nueva España, Libro V, capítulo XXX, pp. 805-810. 
XVIII, la explicación fundacional de Zacatecas estuvo centrada en los sermones que los franciscanos pronunciaron en torno a Guadalupe. Para ello baste hacer mención del sermón predicado por Cosme Borruel, misionero apostólico del Colegio, con motivo de la dedicación del Santuario que se edificó en la Bufa. José Mariano Esteban de Bezanilla -en su Muralla zacatecana- recupera algunoos fragmentos del sermón de Borruel: "Habiendo tradición verbal que diga vieron los indios en ese día una imagen de esta Señora, milagro que dio motivo a que se diesen la paz" ${ }^{6}$ La transmisión de la idea de que la Virgen de Guadalupe se pasó del cerro del Tepeyac a la Bufa, es una de las constantes en los sermones del siglo XVIII, para otorgar la legitimidad necesaria en torno a la idea de la conquista hecha por los españoles a los bárbaros chichimecas. Que la reina de los cielos amuralle a esta ciudad con su celestial patrocinio. $^{8}$

6. Citado por José Mariano E. de Bezanilla Mier y Campa, en: Muralla zacatecana de doce piedras preciosas erigidas en doce sagrados títulos y contemplados en el patrocinio y patronato de su augustísima patrona y Señora María Santísima, 1788, reimpresa por El ilustrador católico, 1909, p. 18.

7 Fr. Cosme Borruel predicó en el día del estreno de la capilla de la Bufa, un sermón que no está localizado, pero que se tiene por lo menos la ficha con los siguientes datos: "La nueva espiritual fortaleza erigida en el más eminente Sitio de la Ciudad de Zacatecas para su resguardo y custodia", Sermón que en las felices estrenas de una nueva capilla, que en cerro vulgarmente llamado la Bufa, fabricó y dedicó a María Santísima con el Título del Patrocinio, el Señor Conde Santiago de la Laguna, en memoria de haber sido este sitio donde asentaron su Real los españoles en el tiempo de la Conquista, que era el mismo donde tenían los gentiles su fortaleza. Predicó en el día de la Presentación de María Santísima, a 21 de noviembre de 1728, el P. Fr. Cosme Borruel, predicador misionero del Orden de N.P.S. Francisco y Lector de Teología en el Apostólico Colegio de Nuestra Señora de Guadalupe. Sácalo a la luz el Señor José Bernárdez, Conde de Santiago de la Laguna y lo dedica a la Muy Noble, Ilustre y Leal Ciudad de Zacatecas, México, Imp. José Bernardo de Hogal, 1729, en: Guillermo Tovar y de Teresa, Bibliografía novohispana de arte. Impresos mexicanos relativos al arte del siglo XVIII, Tomo II, México, FCE, 1988, p. 372.

8 Relata Bezanilla : "Pocos años antes que pusiese en él la primera piedra, se dignó aparecer al dichoso neófito Juan Diego en el monte de Tepeyac. Prometiole ser tierna madre de todos los naturales de este reino y de cuantos solicitaran su protec- 
El discurso guadalupano registrado en los sermones se ubica para este tiempo novohispano dentro de la tradición barroca, cuya eficacia reside no sólo en el horror al vacío y la obsesiva recuperación de metáforas, sino en el modo en que el juego del claroscuro determina la propia argumentación. Los sermones barrocos, por tanto, penden de los contrastes: para hablar del bien, qué mejor que compararlo con el mal, para hablar de Jesús, el demonio y sus demonios son puestos en escena, ${ }^{9}$ para hablar de Guadalupe el contraste con la Virgen del Pilar.

El tópico de la Guadalupana se constituyó en un elemento central en la estructura artificiosa del sermón barroco. En 1.732, el mismo Cosme Borruel predicó un sermón en el día de Nuestra Señora de Guadalupe, el cual, desde el mismo título, ofrece una construcción barroca basada en la contraposición: "La imagen más clara de lo más oculto de María". ${ }^{10}$ Para el predicador es menos lo que

ción, dándole en su misma tilma por señal y prenda de la infalibilidad de su promesa, la maravillosa pintura de su imagen de Guadalupe. (...) En virtud de esa promesa a los catorce años ocho meses y veintiséis días pasó del monte de Tepeyac al de la Bufa, en donde mirando como hijos a los indios y cuidando de los españoles como tierna madre, subyugó a los unos, amparó a los otros mostrándose precioso Chrysopraso en quien brillan los tres colores: verde, rojo y dorado, o por mejor decir, por esta misma causa refulgentísimo Iris, que unió con el estrecho vínculo de la paz estas tan diversas naciones. Así se efectuó la zacatecana conquista por María y María de Guadalupe (...), pues la imagen de los de Zacatecas que efectuó su conquista, sólo carecía de las estrellas para ser de Guadalupe (...) y así la reconoció la ciudad, venerándola por su titular y patrona en el misterio de su Inmaculada Concepción", en: Muralla zacatecana... Op. cit., pp. 170 y 171.

9 En el Archivo Parroquial de Zacatecas se encuentra una serie de sermones cristológicos, en donde está presente la figura del demonio. Estos sermones manuscritos que nosotros llamamos "sermones formales", son diferentes a los impresos en tanto que no recuperan la historia cultural zacatecana, no hay datos sobre su población, ni se exponen problemas de tipo social, tienen que ver más con la homilía. Mientras que los sermones impresos que llamamos "de circunstancia", implican un motivo que le viene de fuera del Evangelio, es decir, son pedidos, mandados hacer por un motivo especial: dedicación de templos, honras fúnebres, rogativas.

10 P.B.E.J., "La imagen más clara de lo más oculto de María", SERmón, que en el día de Nuestra Señora de Guadalupe en su Colegio Apostólico de Zacatecas, año de 
se puede decir sobre María y más lo que no se puede decir; ${ }^{11}$ es sólo la perfección de su cuerpo lo que se puede mostrar en una pintura, pero ésta "nada nos dice de lo que en su interior se oculta"; ${ }^{12}$ en esta imagen, como en el Evangelio, está el Sol dentro de la Señora, pero en la imagen "prorrumpen en el exterior los rayos" que en el vientre de María están ocultos, esto es: "la misma Señora vistiendo ăl Sol lo oculta y vestida del Sol lo manifiesta; porque esta Divina imagen manifiesta todo lo que en su útero se oculta." ${ }^{13}$ Borruel y su argumentación dialéctica de los contrarios, recurre al Apocalipsis en que "apareció una grande señal, dice el evangelista, y fue una mujer vestida del Sol. No puede negarse que es singular prodigio. ¿La frágil naturaleza de una mujer, con vestido de tanto ardor?” Y más aún, ¿cómo se pudo identificar entre tanta luz el sexo, cómo pudo Juan ver que esa mujer estaba preñada? -se pregunta el predicador. ¿A quién tiene en su útero?, pero el evangelista lo calla "luego, lo que tenía en el útero se nos queda oculto (...) esta mujer preñada está del Sol vestida, ¿a quién podía tener en su vientre, sino a todo el Sol de Justicia?" Las relaciones de contrarios entre luz-oscuridad, interior-exterior, lo oculto y manifiesto tejen la red que explica el suceso; el predicador reconoce lo difícil del asunto, pero va deshilvanando su artificio con las pruebas argumentativas que unen estos contrarios:

...en mi sentir parece que hablan proféticamente del modo que expresa la maternidad de María esta imagen de Guadalupe. En esta imagen está Cristo

1732 predicó el P. Fr. Cosme Borruel, predicador apostólico y lector de teología en dicho Colegio, México, Imp. José Bernardo de Hogal, ministro e impresor del Real y Apostólico Tribunal de la Santa Cruzada, 1733.

11 Este tipo de declaraciones sobre lo "inefable" tienen que ver con la propuesta agustiniana del tiempo. San Agustín se pregunta ¿qué es el tiempo? "cuando nadie me lo pregunta, lo sé; pero si me lo preguntan y quiero explicarlo, no lo sé", Confesiones, México, Ediciones Paulinas, 1981, pp. 236-237.

12 Borruel, Doc. cit. s/n.

13 Doc. cit. s/n. 
concebido y oculto, pero al mismo tiempo nacido y manifiesto; porque no viéndose el Sol y mirándose sus rayos, es lo mismo que decirnos que porque dentro de María está el Sol, prorrumpen sus rayos en la exterioridad (...) Nace el Divino Verbo humanado de María y se queda en ella; nacen de esta imagen todos estos rayos y se queda el Sol dentro de esta imagen, porque sólo esta imagen nos representa con claridad, que es María por ser madre de Cristo una imagen expresa de la generación del Padre Eterno. ${ }^{14}$

Bajo este tipo de argumentos, la retórica sermonaria del siglo XVIII en Zacatecas fue construyendo una imagen contrastante de Guadalupe. Los predicadores franciscanos se ocuparon en sus sermones de reconstruir el relato del Tepeyac para adecuarlo a la Bufa y al momento de la conquista de Zacatecas. Atrás de su pluma, se encontraba la formación retórica y teológica cifrada en "manuales para el predicador" y "repertorios sermonarios" que eran traídos desde España y eran leídos, consultados y recreados en sus sermones a manera de citas al margen del texto, autoridades como San Agustín, Antonio Vieyra, el padre Flores o Ricardo de San Laurencio, entre otros. ${ }^{15} \mathrm{El}$ caso de Borruel (recordemos que era profesor de Teología en el Colegio de Guadalupe) y el sermón antes citado, trae al margen el tipo de lecturas que recuperó para otorgar a su argumentación criterios de autoridad: "Ya lo dijo San Agustín" o "San Pablo." De San Agustín cita las Confesiones, De Doctrina Cristiana y algunos de sus sermones, de Ricardo de San Laurencio, un fragmento de uno de sus sermones para fortalecer el argumento de contrarios en torno a la Virgen:

Parece fingida para lo dicho una autoridad de Ricardo de San Laurencio: Nota quod MARIA facta est amictus solis justitiae, quado ipsum carne mundissima induit, et amicta ipsa Sole Filium portans in Utero. Vean aquí, seño-

14 Doc. cit. $\mathrm{s} / \mathrm{n}$.

15 La Biblioteca Elías Amador, ubicada en el museo Pedro Coronel de la ciudad de Zacatecas, actualmente custodia más de 22,000 volúmenes que circularon en los diferentes conventos de la ciudad hacia el período novohispano. 
res, según el citado a MARÍA a un mismo tiempo vestida de Sol: Amicta Sole y vistiendo al Sol: Facta est amictus Solis; y todo fue cuando tenía a Cristo en su útero: Quando ipsum carne mundifsima induit Filium portans in Utero. ${ }^{16}$

Sin embargo también hay una jerarquía entre las autoridades traídas a los sermones franciscanos en Zacatecas: las voces de los èvangelistas son las reconocidas por los frailes como el mejor modelo para su argumentación, de ahí que se recupere a Mateo, Lucas, Juan y Marcos. Para el caso de la Guadalupana, los sermones traen como principalísima autoridad la voz de Juan y su relato del Apocalipsis. Veamos el caso de Borruel y cómo fundamenta su discurso usando argumentativamente la autoridad del evangelista Juan y su visión apocalíptica:

Vamos a un texto que puede ya llamarse del Sermón de Guadalupe el Augustino; porque no hay sermón de esta Imagen Soberana en que no se proponga. Es común, procuraré, que parezca singular: Signum magnu apparuit in Coelo, mulier amicta Sole: aparecióse una grande señal, dice el Evangelista, y fue una mujer vestida del Sol. ${ }^{17}$

La tradición misionera franciscana y la predicación guadalupana fueron alimentando la imagen milagrosa de una piadosa madre que abogaba por sus hijos. Sin embargo, no sólo el discurso sermonario contribuyó a la edificación del culto guadalupano en Zacatecas. Podemos decir entonces que en Zacatecas, quienes ayudaron a edificar desde su retórica la imagen portentosa de la Guadalupana fueron los franciscanos. Su discurso era parte de una práctica que buscaba consolidar un mundo representado en milagros, apariciones y símbolos inefables. Empero, atrás del mundo simbólico de la aparición que encierra el relato de Guadalupe en el Tepeyac y que fue recuperado por los franciscanos en Zacatecas a partir de la

16 Doc. cit. s/n.

17 Doc. cit. s/n.

108 I C C A 
producción sermonaria, hay grupos sociales que también demandan la apropiación del mito y en su demanda se puede leer e interpretar una lucha por demostrar la piedad y la preeminencia social. El cabildo y sus hombres con su "católica prudencia", mostraron una vez más que la piedad traspasa el ruego y la oración individual, la piedad es un campo en dónde practicar y evidenciar la preeminencia. Nuestro relato sobre Guadalupe no se centrará por tanto en la discusión que ya entablaron los aparicionistas y los antiaparicionistas, sino en la necesidad cultural que implicó para ciertos grupos su apropiación.

\section{UNA VIRGEN PARA UN MILAGRO}

William Taylor, estudioso de las tradiciones religiosas en México, señala que "durante la epidemia de 1737, líderes religiosos hicieron rogativas especiales por todo México a la imagen de Guadalupe, se hicieron frecuentes peregrinaciones a su iglesia localizada en las afueras de la ciudad de México y su imagen fue ampliamente reconocida por haber puesto fin a la epidemia." ${ }^{18}$ En este contexto, en septiembre de 1737 el cabildo de Zacatecas recibió noticia desde la ciudad de México de hacer la función del voto y juramento de Nuestra Señora de Guadalupe como patrona de esta ciudad por haber hecho el milagro de salvar a la población de tan terrible peste. El Cabildo acordó como día de la celebración el 15 de septiembre "con las debidas demostraciones de júbilo y alegría que corresponden a la utilidad que se previene de tan poderoso patrocinio a que todos los vecinos se hayan animado a concurrir gustosos así como luminarias en los tres días precedentes como con otras invenciones

18 William B. Taylor, "Nuestra Señora del Patrocinio y Fray Francisco de la Rosa: una intersección de religión, política y arte en el México del siglo XVIII", en Relaciones. Estudios de historia y sociedad, No. 73, Zamora, El Colegio de Michoacán, invierno de 1998, p. 306. 
de fuego que particularmente se previenen." ${ }^{\prime 19} \mathrm{El}$ voto y juramento se hizo en la iglesia parroquial mayor adecuándole una sombra por no tener techo, con la asistencia del cabildo, los curas y canónigos. ${ }^{20}$

Don Miguel de Moraña y Mendoza, alguacil mayor y regidor interino, pidió que el escribano hiciera una relación en el cuaderno de acuerdos de la descripción puntual de todo y "que se principie en el presente año, la observancia de dicho juramento celebrándose fiesta en el día de la aparición de dicha Santísima Señora a costa de los propios de esta ciudad". Pidió asimismo que por haber sido aplaudidos los sermones predicados por fray Agustín de Miquesena, comendador del convento de Nuestra Señora de la Merced y por el Padre Tomás de Sandoval, de la Compañía de Jesús, se den a la imprenta también a costa de los propios de esta ciudad, "dedicándolos en nombre de este cabildo, a la grandeza de su excelencia, el Señor Arzobispo por haber sido quien ha promovido en todo el reino, el patronato de dicha Santísima Señora". ${ }^{21}$ Desgraciadamente no contamos con los sermones del mercedario y del jesuita, sin embargo, es sugerente que en semejante ocasión no se hubiera manifestado la predicación de los frailes franciscanos.

Para noviembre del mismo año el cabildo determinó que la observancia del juramento se hiciera en la propia iglesia del Colegio Apostólico en el día de su aparición gloriosa, el 12 de diciembre, con rezo y octava, librándose la cantidad de 100 pesos para que el escribano se los pasara al síndico de dicho Colegio, de quien recogería recibo participándole esta providencia al guardián, quien a su vez tendría la tarea de invitar anualmente al cabildo y éste debía asistir bajo reales mazas y, una vez terminada la fiesta, se regresaría a su sala de ayuntamiento. Por esas fechas, es necesario recordar que Zacatecas vivía también la epidemia pestilencial; el pro-

19 A.H.Z., Fondo: Ayuntamiento, Serie: Actas de Cabildo, año de 1737, s.n.f.

20 Salvador Vidal, Miscelánea.Datos de la época colonial comprendidos en los años 1578-1810, Zacatecas, Imp. del Gobierno del Estado, 1972, p. 60.

21 A.H.Z., Fondo: Ayuntamiento, Serie: Actas de Cabildo, año de 1737, s.n.f. 
blema de la asistencia a los enfermos se traducía en la escasez de camas en el hospital de San Juan de Dios; el cabildo determinó para ello que se pusieran en dicho hospital "otras cincuenta camas, las doce de ellas proveídas con colchones para las personas más decentes y las 38 restantes en el mejor modo que se pueda". ${ }^{22} \mathrm{El}$ ejercicio de la piedad se manifestaba en estas situaciones de emergencia a través de las limosnas semanarias y de la cantidad de 50 pesos que Dionisio González Muñoz, mayordomo de la ciudad, debía emitir. El ejercicio de la piedad dividía sus dineros: 50 pesos para las camas de los enfermos y 100 pesos para el costo de la fiesta.

Los gastos de la fiesta se concentraron en pólvora, toros encohetados y seis armados, chicharras, cera, luminarias (puestas en la parroquia, en la Compañía y en las casas del corregidor, los alcaldes ordinarios y los regidores), flores, un arco de flores para la puerta de la iglesia de la Compañía, la función de dos madrugadas, vísperas, sermón, misa, pago al sacristán de la Compañía de Jesús por poner el altar (clavos, tachuelas y alfileres), al cochero por su trabajo en el convite de las sagradas religiones, a los cargadores por cargar la cera, a los músicos (violines), chirimiteros, al que toca la caja, al clarinero, al cochero que condujo al orador, a los ministros diácono y subdiácono, al campanero por los repiques. El total de gastos fue de 617 pesos 3 reales. La intención de realzar el evento por parte del cabildo también puede notarse en esta cantidad, pues haciendo referencia con otras fiestas en ese mismo año tenemos que: para la fiesta del Patrocinio se gastaron 52 pesos; para la fiesta de Naves, 104 pesos; para la fiesta del cumplimiento de años del Rey, 332 pesos. ${ }^{23}$

La fiesta de Guadalupe fue un compromiso a cumplir anualmente. El voto y juramento ya se había dado por esta nobilísima ciudad, en donde el cabildo juntó a las sagradas religiones para reali-

22 A.H.Z., Fondo: Ayuntamiento, Serie: Actas de Cabildo, año de 1737, s.n.f.

23 A.H.Z., Fondo: Ayuntamiento, Serie: Actas de Cabildo, año de 1737, fojas: 67-69v. 
zar el evento. El voto a Guadalupe además de la muestra de piedad que los devotos pudiesen demostrar, era un compromiso con el cabildo metropolitano de seguir en Zacatecas el culto a Guadalupe.

Si bien este culto se fue dando entre novenarios, procesiones y sermones, también se fue definiendo entre los desacuerdos de los grupos sociales; el culto guadalupano hacia la mitad del siglo XvIII, fue estableciendo una tensión entre el mundo religioso a extramuros con los franciscanos y el mundo elitista que implicaba al cabildo. Algunos de los eventos que ayudan a mostrar las tensas relaciones entre los grupos que circundaban la imagen de Guadalupe, pueden verse desde la celebración de diciembre que se realizaba en las instalaciones del colegio con la asistencia del cabildo bajo reales mazas. En 1742 el colegio se privó de que el cabildo autorizase su solemnidad (con gran dolor y congoja común de sus religiosos) y celebrase por su parte en él la festividad de Guadalupe como su patrona jurada; el escribano del cabildo había pasado a preguntar al bachiller Juan Modesto de Rivera Bernárdez si el día en que se celebraba en el colegio la aparición de la Virgen asistiría o no como patrón, ante la indefinición de éste porque "lo habían tomado desprevenido", el cabildo prefirió realizar la festividad en el colegio de la Sagrada Compañía de Jesús. Un año después, se reconoció a Juan Modesto Rivera como patrón del colegio; su guardián Andrés de Aragón, escribió al cabildo lo siguiente:

En este presente año y los sucesivos (...) todos los padres de este colegio prerrogan a Vuestra Señoría rendidamente y en su nombre, se sirva de continuar como antes honrando con su asistencia, bajo sus reales mazas la festividad de aparición de Nuestra Señora de Guadalupe, que el día 12 de diciembre como en su propio día se aplaude y solemniza dignándose Vuestra Señoría al mismo tiempo de proseguir con la festividad que a dicha Santísima Señora tiene jurado celebrar, esperando como espera este colegio de la benignidad de Vuestra Señoría, que así se sirva de providenciarlo por ceder en el mayor culto y veneración de dicha Santísima Señora como que ésta es su propia casa, cuyos alumnos siempre viviremos obligados y reconocidos a este favor. ${ }^{24}$

24 A.H.Z., Fondo: Ayuntamiento, Serie: Actas de Cabildo, año de 1743, f: 255 y 256. 
La casa "natural" de Guadalupe era el colegio, según estaba entendido: los franciscanos le pedían al cabildo que asistieran a la celebración de Guadalupe porque la casa de la Santísima Señora estaba ahí y no en otro lugar. Pero las noticias desde México no llegaban siempre a la casa natural de Guadalupe; por ejemplo en 1749 desde la ciudad de México se dirigió una carta al cabildo de Zacatecas para que éste moviera los corazones de sus vecinos y cooperaran a la piadosa y útil obra del culto de la Soberana Reina de Guadalupe en la construcción de la arquería para la conducción de las aguas a su santuario; ante esta petición, el escribano citó al vecindario para advertir de esta carta y se "excitara y moviera los ánimos para que la piedad de ellos haga demostrativo alarde de su garbo en obsequio y culto de Nuestra Patrona y Soberana Reina"25 Entre los favores y las concesiones pueden observarse varias líneas de relación: de la ciudad de México al ayuntamiento de Zacatecas, del ayuntamiento al colegio y del colegio al ayuntamiento. Los mismos frailes reconocían la necesidad de mantenerse en buenos tratos con los miembros del cabildo y éste finalmente también necesitaba de la participación del colegio para los momentos difíciles y pedir sus oraciones y sermones. En 1751, ante el reconocimiento de lo que significaba esa relación de favores recíprocos, José María de Guadalupe y Alcivia, predicador y misionero del colegio pidió de la caridad del cabildo para ofrecerle a la imagen de Guadalupe el retablo que "le es tan debido y se le dé culto que a su soberano patrocinio debe nuestra obligación" y dado que en la fábrica de dicho retablo no hay fondos para su dorado más que "el de la caridad de sus fieles y siendo tan sabido el generoso celo de Vuestra Señoría, le suplico se sirva de concurrir a obra tan del agrado de la Señora su Patrona Jurada con aquella limosna que sus propios puedan reportar. ${ }^{\prime 26}$

25 A.H.Z.. Fondo: Ayuntamiento, Serie: Actas de Cabildo, año de 1749, f: 146, 160, 161.

26 A.H.Z., Fondo: Ayuntamiento, Serie: Actas de Cabildo, año de 1751, f: 40. 


\title{
LA PIEDAd Y SUS OBJETOS: ENTRE LA PRELAdITA
}

\author{
Y LA IMAGEN EN LIENZO
}

La tensión de las relaciones entre el cabildo y el colegio puede también observarse en la serie de demostraciones de júbilo que el cabildo organizó con motivo de la confirmación realizada por el papa Benedicto XIv, en su breve del 25 de marzo de 1754, del Patronato de la Virgen María en su imagen de Guadalupe, declarándolo universal a todo este reino. El 11 de marzo de 1758, el cabildo de Zacatecas recibió desde la ciudad de México, una carta en donde se adjuntaba el breve de Benedicto XIV, el cual ponderaba la serie de milagros que, gracias a la intercesión de la Virgen de Guadalupe, la población de la Nueva España había experimentado:

$\mathrm{Ni}$ es de maravillar que cada día haya crecido la devoción cuando fuera de los milagros que en toda Nueva España se cuentan haber acontecido, el mismo cabildo de México afirme poder esperarse el presente auxilio y libertad de la epidemia (como de facto aconteció el año de 1727) por la intercesión de la Santísima Virgen, porque ese mismo había experimentado la ciudad mexicana en el año de 1696 y 1697, en el que convertido el pueblo a la beatísima virgen, se libertó de la inmensa mortalidad; esto mismo se experimentó en el año de 1665 y 1666, pero principalmente en el año de 1629, contra una peligrosa inundación de las aguas. Fuera de esto añade el cabildo metropolitano de México que es constante y tradición sin duda, que infestando antes los poseídos y obsesos en gran copia aquellas regiones y hablando por obra diabólica las estatuas de los ídolos, después de la aparición de la Santísima Virgen, ninguno de estos males acontecen, el cual beneficio, así los indios como españoles, le atribuyen a esta Santísima Virgen (...) Ni solamente aquella diócesis mexicana, sino toda la parte de la América, que se nombra la Nueva España tiene gran devoción a este santuario. Entre otros oficios de piedad, fue aquel especial, que cundiendo en el año de 1737 por aquella región la peste, estableció tanto el gobierno secular como el cabildo, elegir en las diócesis de la Nueva España en Especial y Principal Patrona a la Santísima Virgen bajo este título de Guadalupe. ${ }^{27}$

27 A.H.Z., Fondo: Ayuntamiento, Serie: Actas de Cabildo, Caja 13, año: 1757, s.n.f. 
El breve señalaba los favores y declaraba la confirmación de Guadalupe como Patrona de la Nueva España. Este documento fue anexado en los libros de cabildo y acatado por sus miembros. Los vecinos de la ciudad de Zacatecas se apresuraron por hacer las demostraciones de júbilo y erogar la cantidad suficiente para hacer una función como lo demandaban las circunstancias. Había que hacerlo cuanto antes, ya que los vecinos de Zacatecas se habían tardado en su demostración, y teniendo en cuenta

que esta ciudad es una de las que más se han especificado en suntuosidad y regocijos en obsequio de sus soberanos naturales, no lo hayan ejecutado en culto y veneración de la Soberana Emperatriz de los cielos y tierra María Santísima Nuestra que se dignó venir a este reino a protegernos en todas las necesidades; y siendo público y notorio a toda esta ciudad de que no ha quedado en todo el reino ciudad, villa, pueblo, hacienda, arrabal que no haya celebrado fiesta con cristiana emulación, sólo ésta ha sido lunar con general noto, por ser una de las principales en que se ha granjeado fama y nombre por sus celebridades, no es tolerable ni cabe en pechos nobles el que se haya de quedar $\sin$ hacer las demostraciones debidas... ${ }^{28}$

El cabildo determinó escribir una carta a los vecinos comerciantes y mineros "de nobles y generosos pechos" para que concurrieran con su piadosa dádiva y se pudiera celebrar tal acontecimiento. El escribano haría una lista con los nombres y cada uno determinaría la cantidad a otorgar. La cantidad recolectada fue de 400 pesos que, aunque no era suficiente, con eso se podía empezar a organizar la fiesta, cuya fecha -determinada en cabildo- sería los primeros días de septiembre en que la ciudad tenía acostumbrada la celebración de las fiestas de Nuestra Señora de Zacatecas. Se asignaba el domingo 3 de septiembre para que la Santísima Reina de Guadalupe que se encontraba en su colegio, precediendo la venia del R. P. Guardián, fuera conducida por la mañana al convento del Señor Santo Domingo en el modo que anualmente se lleva su

28 A.H.Z., Fondo: Ayuntamiento, Serie: Actas de Cabildo, Caja: 13, año: 1758. 
novenario, para traerla por la tarde a la parroquia mayor de esta ciudad en procesión solemne, para lo cual preceda súplica por los diputados que se nombrarían para que concurran con sus comunidades y Santos Patriarcas. Y el día lunes 4, se le suplicaría

al Señor Vicario y cura de esta ciudad que con su clero hiciera el primer día la función de iglesia, y en la misma conformidad los días siguientes martes 5 , miércoles 6 y jueves 7 a los prelados de Santo Domingo, San Francisco y el Colegio de la Compañía de Jesús, haciendo en las noches de estos días (...) los fuegos y demás que arbitraren para la mayor celebridad, moviendo asimismo a los gremios con el fin de hacer lo conveniente en la demostración de dicha función, para lo cual se dé la plena facultad a los dos diputados que han de correr con dicha función que por derecho se requiere, para que muevan cuanto arbitraren al mayor lustre de la festividad.

Se mandaba -como antigua costumbre- que el alcalde ordinario Juan Manuel Gutiérrez apadrinase en todo a Juan de Rábago Terán, alférez real, en la función del pendón en anual memoria de la conquista de Zacatecas, cuyos costos para el refresco y la fiesta se estimaban en 200 pesos, para lo cual se despachaba libranza contra José Joaristi, en quien paraban los ramos de propios.

José Joaristi y Francisco Javier de Aristoarena y Lanz fueron los diputados nombrados comisarios de la fiesta, ambos como reconocidos hijos de Zacatecas, hombres afortunados en minería y comercio; ${ }^{29}$ ambos "personas en quien concurren las circunstancias propias (para organizar la fiesta) que procurarán con esfuerzo acomodándose a lo que se ha juntado y a los arbitrios que dichos señores tuvieren por oportunos, para lo cual se les confiere por este cabildo, toda la acción que corresponde, como también el que puedan promover a los gremios para que hagan sus demostraciones y juntamente se les deja a su arbitrio el convite y distribución de los días, (...) que los diputados dispongan como mejor les pareciere..." ${ }^{930}$

29 Cfr: Amaya Garritz, "La formación del diccionario bio-genealógico de los vascos en Nueva España”, en: Genealogía de las dos fronteras, 1996.

30 A.H.Z.,Fondo: Ayuntamiento, Serie: Actas de Cabildo, Caja 13, año de 1758, s.n.f. 
Por su parte, el cabildo disponía que el escribano debía salir acompañado del portero, atabaleros y clarineros a casa del alcalde ordinario de primer voto para que en su compañía sacara al alférez real y lo trajera a las casas reales, en donde estaría el Corregidor, el alcalde ordinario de segundo voto, los señores regidores y los diputados. Asimismo se acordaba que el corregidor se sirviera de mandar al Gran Turco a las casas reales con toda su morisma para que en orden siga dicho paseo, y después de los moros, las mulas que han de sacar los toros muertos. El cabildo acordaba también que en agradecimiento, como es debido, se les participe a los diputados que tienen lugar asignado después del regidor decano en la banca del cabildo para las funciones de iglesia y los toros. La esposa del corregidor, Doña Gertrudis Díaz de la Campa, debía convidar a las señoras de la república para el tablado de este cabildo en los toros. ${ }^{31}$ Precisamente fue a partir de ese año en que el cabildo dispuso que los toros no salieran más a la calle, "como hasta la presente se ha practicado, pues es causa de motines y ruido entre la plebe sobre la competencia de la cola, como asimismo se impide que se lidien los toros al administrar los santos sacramentos por el temor de no encontrarse en la calle con los toros y que se expone a que en las calles por donde corren haya muchas averías y desgracias" . ${ }^{32}$

Todos estos preparativos se hicieron dos meses antes de las demostraciones. Aristoarena y Joaristi, como comisarios de la fiesta, mandaron retratar los mismos tamaños de la Santísima Señora original en un lienzo "con el fin no sólo de que sirva para las presentes celebridades, sino para que después se remita a la Muy Noble y Leal Ciudad de México para que sirviéndose Su Señoría de mandarlo retocar, se coloque como Patrona en la parroquia mayor de Zacatecas". Este fue el motivo de una nueva tensión entre el cabildo y los franciscanos.

31 Ibid.

32 Ibid. 
Al cabildo se le participó que el Colegio de Guadalupe había formado una fuerte queja culpando a los referidos señores diputados por desafectos a aquella sagrada comunidad como por poco considerados, pues mandaron hacer un lienzo omitiendo el traer a la Santísima Señora que de talla y muy pequeña estatura se venera en el apostólico colegio. Frente a la queja de los franciscanos, los diputados refirieron al cabildo esta incómoda y dolorosa situación para ellos, pues lo que habían hecho era desempeñar su obligación "y no teniendo el más leve motivo para dar qué sentir al apostólico colegio, pues ambos han sido y son tan amartelados por el particular de sus religiosos y sagrada religión..." Joaristi y Aristoarena acudieron al cabildo, para que éste arbitrara y resolviera, "esperando su protección". La respuesta del cabildo fue que "no alcanza motivo alguno para que el colegio haya formado queja de los señores diputados sobre la expresada representación, pues todo lo que han ejecutado ha sido en virtud de las facultades que este cabildo les ha conferido con la gran experiencia y satisfacción que tienen de su acertada conducta, como lo han acreditado en las presentes disposiciones con que han promovido la celebridad de la Santísima Patrona de Guadalupe. El cabildo señalaba que para evitar cualquier indisposición y desazón que pudiese ser originada del "ignorante vulgo sugerido del demonio quien como enemigo común tira a deslucir los obsequios que se hacen en que le pisó la cerviz y no persuadido su Señoría de que en la doctitud de un religioso colegio se haya introducido tal vulgaridad, y para que ésta se extirpe, el cabildo mandaba se escribiese una carta al guardián expresando el haber llegado a noticia de su Señoría la vulgaridad de lo manifestado y, según lo que respondiere el reverendo padre, dar las providencias que correspondan. ${ }^{{ }^{33}}$

Los términos de la carta se centraban en el apoyo irrestricto a los comisarios de la fiesta, justificando su actuación al decir que no

$33 \mathrm{Ibid}$.

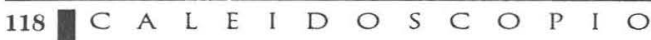


estaban solos, que las disposiciones realizadas para mandar traer el lienzo desde la ciudad de México eran acuerdos establecidos por el propio cabildo. Ante esto, los religiosos del colegio contestaron que "esto de mudar inopinadamente a los pueblos el objeto de su devoción, no puede menos que causarles una notable extrañeza con menoscabo de su religión y culto. La imagen de Guadalupe que se venera en esta iglesia, está muy entrañada en los corazones de sus habitantes por los repetidos beneficios (y que llaman milagros) que reciben, dirigiendo a ella sus plegarias." Junto a este argumento en que se exponía como causa primera la piedad popular, los religiosos afirmaban que hacía pocos años Zacatecas había jurado como patrona a Guadalupe, precisamente con la imagen que se veneraba en el colegio; prueba de ello -sentenciaban- era que el mismo cabildo bajo reales mazas, asistía anualmente a la fiesta de Guadalupe.

Juntamente ve todo el pueblo que de muchos años a esta parte es pedida esta imagen y conducida a la ciudad por sus cabezas seculares y eclesiásticas en procesiones públicas, y se le hacen novenarios y rogativas por falta de aguas, o por inundaciones o por enfermedades, $y$ siempre con los efectos misericordiosos que se desean de la diestra del Altísimo por la intercesión de su madre Virgen con que en la ocasión presente en que se celebra la confirmación apostólica del mismo patronato, si se le varía a la devoción del pueblo llano el objeto, no será de extrañar su tediosa admiración.

Los religiosos sugerían una posible solución al conflicto: que la imagen de los diputados se colocase en el altar y la de este colegio que mira el pueblo con especial devoción, se llevase para la fiesta y procesión pública.

Aún con una posible solución planteada, José María de Guadalupe y Alcivia, capellán del colegio, mandó un mensaje al cabildo ratificando el argumento de que la imagen de bulto de la Santísima Prelada y la veneración que se le tiene "no ha nacido de los religiosos, sino de la suma devoción de muchos vecinos de esa ciudad, de todas las jerarquías y sexos, cuyas voces han hecho eco aún dentro 
del claustro, de donde no ha salido influjo alguno, antes bien, se han repelido las quejas de los seglares, por lo que por lo mismo ha pasado, pues las ocasiones que he ido a esa ciudad me han importunado interpelado por la causa de no llevar a dicha imagen, para cuya respuesta me he valido de los medios prudentes que he alcanzado." Alcivia sostenía que podría impedir a los vecinos de esa noble ciudad (que no eran sus súbditos) que formularan sus quejas por el hecho de que la imagen de la Preladita no se llevara a la festividad. Alcivia advertía que no se culpara a los religiosos de su colegio de las opiniones contrarias a la sugerencia de los diputados de traer otra imagen, "ni se presuma que de su parte haya influjo en los seglares que indiscretamente censuraren o culparen lo operado por los diputados comisarios;" para evitar cualquier responsabilidad respondía que: "ninguno de mis súbditos de cualquier condición, aunque sea un donador o limosnero ponga el pie en la ciudad de Zacatecas hasta finalizadas todas las fiestas y celebridades de Nuestra Señora de Guadalupe. Con esto se impedirá cualquier mortificación que a vuestras mercedes pueda provenir de lo que se dijere o hablare y quedarán satisfechos de lo mucho que los estimo y mi ciega obediencia acredita, la que protesta en los demás preceptos que se sirvieren imponerme."

El cabildo determinó que este grave problema debía ser tratado por los licenciados Joaquín Antonio de Silva y Agustín José García, "para que consulten uno y otro y determinan con la brevedad que pide el caso, la respuesta que se ha de dar a los reverendos padres". Los abogados sugirieron que, frente a las cartas enviadas por los religiosos, lo mejor era no contestar por el momento y que privara la prudencia trasladando la discusión en las escuelas y "por ningún modo controvertirse entre Vuestra Señoría y el sagrado apostólico colegio y mucho menos en ocasión tan importuna como la que ocurre, en la cual, con solamente que se omita dar respuesta a dichas cartas, se suspende o corta el hilo de la ya amagada, si no iniciada desazón." Los abogados dirimieron el conflicto y propusie- 
ron que mejor todas las voluntades se unieran en la gloriosa ejecución de las festivas y suntuosas demostraciones del mariano afecto y devoción, como por medio de sus maduros acuerdos y del fervoroso vigilante celo de sus diputados y de la generosidad zacatecana expresada en estos preparativos costosos de la fiesta. Los abogados sentenciaron que lo mejor era ocuparse en el verdadero motivo de estos universales júbilos, para lo cual nuevamente en su escrito traían la historia del juramento hecho por la ciudad de Zacatecas en 1737 y lo que ello significaba en cuanto a protección por la madre guadalupana. Referían que el pueblo de Zacatecas no podía venerar la imagen original, dada la lejanía en que se encontraba, pero que el pueblo cumplía en su devoción frente a cualquier copia de aquel aparecido milagro. Si el cabildo promovía traer otra imagen de Guadalupe, ello no significaría el detrimento o menoscabo del culto. Y sobre la amenaza hecha por el capellán Alcivia, lo mejor era que privara la prudencia y que V. S., a través de uno de sus regidores, hiciera patente y manifestara al guardián de dicho colegio que todos debían asistir a las funciones "para que así se satisfaga de no haber en V. S. ni en los moradores de esta ciudad novedad en el cordial afecto y veneración con que siempre han sido atendidos aquella religiosísima comunidad y sus individuos".

El cabildo mandaba a su escribano con el alguacil mayor para convidar nuevamente a los religiosos del colegio a la fiesta, pero también los mandaba para leer la argumentación establecida por los licenciados y que procurasen quedaran los reverendos padres satisfechos de la paz, quietud y sosiego en que el cabildo y sus diputados procuraban el mayor culto de la Santísima Señora de Guadalupe, "sin que se llegue a imaginar el que en los diputados haya habido la menor disposición sin ser consultada y aprobada por el cabildo." Después de haber establecido lo anterior, un día antes de iniciadas las fiestas, el dos de septiembre, los frailes nuevamente se dirigieron al cabildo por medio de otra carta, en donde expresaban su pesar por la obstinación de los diputados, considerando esto 
como un estorbo para que los frailes asistieran al festejo. En esta misiva hacían alusión a la carta que el propio cabildo les mandó, sin embargo, los frailes seguían observando por parte del cabildo "una ratificación indirecta de la calumnia que falsamente se nos ha impuesto". Solicitaban abiertamente que los diputados se retractaran de haber dicho lo siguiente (lo cual fue recuperado textualmente por los franciscanos): "muchos de los reverendos padres de este colegio no sólo han tenido a mal el que hubiésemos mandado copiar a la Santísima Señora en lienzo (como debe ser), sino que por no haber traído la que los padres tienen de talla y chica, nos culpen de desafectos a la sagrada religión y han impuesto e informado a muchos seculares, de que va resultando indisposición, en la disposición que tan discreta se ha hecho". Joaristi y Aristoarena le pedían al guardián del convento que no censuraran más lo ejecutado, este otro argumento también era puesto textualmente por los prelados: "lo que nos obliga a repetir a vuestro padre reverendo la súplica que se digne mandarles a los reverendos padres se contengan culparnos, pues si hubiera culpa o agravio (que lo hay) en lo operado, deberá ser responsable el muy ilustre cabildo y no sus diputados." Por todo lo anterior, Alcivia volvía a impetrar la decisión de que los miembros del colegio no se presentaran a la fiesta.

Estando así las cosas, llegó al cabildo otra carta de los religiosos, pero ahora firmada ya no sólo por el capellán, sino por los frailes Juan Martínez de la Parra, José de María, Ignacio de Torres y José Patricio García de Jesús, quienes ratificaban el hecho de sentirse ofendidos por la actuación de los diputados y además pedían no asistir a la celebridad de la fiesta. El cabildo providenció que se leyera la carta a los diputados Joaristi y Aristoarena y expresaran su parecer. Éstos respondieron entonces con el intento de ofrecer a la luz pública la descripción de las fiestas junto con los sermones pronunciados en ellas, "con el fin de que se difunda y perpetúe por medio de las láminas que estamos determinados a costear, para que ya que no podemos desempeñar a medida de 
nuestro fiel deseo la confianza que a V. S. hemos merecido, siquiera acreditemos el afecto a ejecutarlo y nuestra propensión a servir siempre a V. S. en cuya demostración: a su nombre y como sus diputados, hemos elegido por mecenas de toda la obra a la Nobilísima e Imperial Ciudad de México que tanto se ha singularizado para con V. S."

Después de las fiestas, el cahildo tomó el siguiente acuerdo en donde mantenía su apoyo incondicional a sus diputados Joaristi y Aristoarena: "de todo lo operado en las fiestas que se refieren con la buena, juiciosa y tan discreta conducta que ha sido y es a todos notoria y con la famosa generosidad que es connatural a los diputados, queda su Señoría no sólo con la más cumplida satisfacción, sino constituida en la mayor obligación para el mejor lustre de esta ciudad." El cabildo, en su apoyo irrestricto a los diputados, confirmaba la feliz idea de éstos de estampar en un texto público todo lo practicado en estos días de septiembre de 1758 en que la ciudad de Zacatecas celebró a Guadalupe. El escribano, a instancias del cabildo, acudió a las casas de Joaristi y de Aristoarena para "tributarles las correspondientes gracias." Si el cabildo a todas luces mostraba su apoyo a sus diputados, también mostraba su desacuerdo con los conventuales: sobre la carta de los franciscanos del 2 de septiembre, la posición del cabildo fue justamente contraria a éstos señalando que: "los reverendos padres quisieron tomar de motivo para desairar al cabildo la idea que tuvieron los diputados de mandar pintar a la virgen"; el desaire y menosprecio -según el cabildono era sólo a sus diputados, sino al cuerpo de la nobilísima ciudad.

Las festividades se realizaron durante las dos primeras semanas de septiembre de 1758. La descripción de ellas es una muestra de cómo los diputados tuvieron no sólo el privilegio de organizar la fiesta, sino de participar públicamente en la procesión cargando la imagen, rodeados del cabildo y de las sagradas religiones Los sermones pronunciados en ellas, reconocían la tardanza de Zacatecas en la celebración, sin embargo, decían: "los últimos serán los pri- 
meros". Los sermones traían nuevamente a colación aquella idea que también Cosme Borruel integraba en su prédica: la Virgen de Guadalupe se pasó del cerro del Tepeyac al cerro de la Bufa, o la idea de la comparación entre Guadalupe y la Virgen del Pilar, reconociendo que es más importante y tiene mayor relevancia ser la mayorazga que la primogénita.

- ¿Qué significó esta festividad de Guadalupe para Zacatecas durante la segunda mitad del siglo XVIII? ¿Por qué los vascos se entregaron sin reservas a la organización de la fiesta y entraron en esta serie de disputas por la imagen con quienes se decían tener la tradición de la devoción popular? ¿Cómo es que una imagen que después fuera integrada dentro de una narración de construcción de identidad nacional, entendiendo a esta nacionalidad como la criolla, puede explicar también la necesidad de apoyar otras identidades que fraguaron la historia cultural novohispana? Así como la microhistoria mexicana ha enfatizado la necesidad de hablar sobre los muchos Méxicos que integran este territorio, reconociendo la diversidad de los procesos culturales en las distintas regiones, así también es preciso reconocer que Guadalupe y el fenómeno del culto guadalupano se vivió y se vive de maneras diferentes: desde la manda a cumplir en la Basílica, hasta el significado que tenía en cuanto a preeminencia social y política el llevar el estandarte en una procesión por algunos vascos que estaban tan cerca, lo más cerca posible de su madre.

\section{LA PROCESIÓN, LA FIESTA, LA PREEMINENCIA}

El mes de septiembre de 1758 el cabildo eligió celebrar las fiestas por dos motivos: porque era el mes de María y su natividad y por la feliz coincidencia con la conquista de la ciudad de Zacatecas. Los comisarios mandaron pintar una copia de la imagen de Guadalupe que fue colocada en la iglesia parroquial. El evento quedó registrado en una descripción de fiestas, en la que se ofrecen mues- 
tras de la solemnidad con que fue preparada la fiesta. La iglesia parroquial se adornó con esmero: "el altar mayor parecía un remedo de gloria y presumo que el ingenioso sacerdote a cuyo cargo estuvo este adorno, no pretendió significarnos otra cosa, imitando en nueve gradas pobladas de ángeles, otros tantos coros, en que se dividen estos soberanos espíritus." ${ }^{34}$

Las calles y plazas de la ciudad de Zacatecas se vistieron de fiesta. Según la costumbre que se determinaba para los días de funciones religiosas, se mandaba adornar las calles, las campanas anunciaban las vísperas, se preparaban las bancas para los miembros del cabildo, se repartían hachas. Fue el día dos de septiembre de 1758 en que se dio inicio esta fiesta a Guadalupe con una comedia representada en la plaza por el gremio de los herreros. Al término y cerca de la noche "se atravesó el manto de sus tinieblas un escuadrón de luminarias que por las calles, balcones y azoteas se las apostaba a competencia." ${ }^{35}$ La plaza principal fue testigo del encuentro entre un toro y sus "toreadores", que sirvió de preámbulo para dos árboles de fuego: "Comenzaron los castillos a disparar sus piezas, y después de haber ofrecido un brillante espectáculo de luces, no bastándose sus bocas para desahogar el interior incendio que los abrasaba, rompieron las ataduras de su prisión y volando unos por la esfera en lucidos escarceos, anunciaban al cielo, como enviados de Zacatecas, la futura solemnidad que se prevenían en la tierra." 36

El día 3 de septiembre y primero de la fiesta, el clero ofició la misa con toda la solemnidad y "gravedad" que requería esta ceremonia. La descripción nos permite acercarnos a este ritual con ma-

34. Breve noticia de las fiestas en que la muy Ilustre Ciudad de Zacatecas explicó su agradecimiento en la Confirmación del Patronato de Nuestra Señora de Guadalupe el mes de septiembre del año de 1758, México, Imp. de los herederos de doña María de Rivera, 1759, p. 11.

35 Ibid., p. 13.

36 Idem. 
yor precisión, pues da cuenta de los principales y su papel en la estructura parafernalia del poder: "A las nueve de la mañana entró el ilustre ayuntamiento y señores comisarios, bajo sus reales mazas, y precedidos de cuatro timbaleros y dos clarines." ${ }^{37}$

Una vez terminada la misa, el gremio de los zapateros participó en estas demostraciones de regocijo con la comedia La escala de la "Gracia. Al término siguió el refresco "que se ministró a todo lo florido del concurso de uno y otro sexo" ${ }^{38}$

El segundo día le tocó su turno a los dominicos. Una vez terminada la misa y el sermón, la tarde lluviosa no impidió la continuación de la función: salió por las calles un carro que era del gremio de los carpinteros, remedando un ancho navío que "daba competente buque a los músicos y a las cantoras" ${ }^{39}$ Quien presidía la popa era la estrella del mar, María SANTísIma dE GuAdaLuPE. En el transcurso se ofreció un coloquio por las casas principales de la ciudad; el día terminó con el estruendo de los castillos.

El día tercero de la solemnidad tocó el turno a la orden de los franciscanos, quienes, según cuenta la descripción, de ser considerados menores por su cualidad de humildad, se tornaron en mayores "no permitiendo ser excedidos de alguno." Hizo muestras de su participación el colegio apostólico de propaganda que, "extramuros de la de Zacatecas, sirve de fortaleza avanzada de esta ciudad, bajo el título también de Nuestra Señora de Guadalupe." ${ }^{\text {4l }}$ La descripción señala en esta parte que el culto a Guadalupe se duplicó, ya que al regocijo público se añadió el regocijo privado que se practica en el colegio. Durante la mañana se ofreció la misa presidida por el presidente del convento Romualdo de Cartagena, "añadiendo al coro ordinario de la parroquial, algunas voces de

37 Ibid., p. 14

38 Ibid., p. 16.

39 Ibid., p. 19.

40 Ibid., p. 21.

41 Idem. 
suyo para desahogar por más bocas el interior extraordinario afecto." ${ }^{\prime 2}$ Por la tarde se ocuparon los canteros y albañiles, quienes conducían un carro triunfal que representaba un templo de tres naves con su torre expresando la analogía con el carro de la gloria de María. Dentro del carro, los músicos "que le daban toda el alma."

El día cuarto participó la orden de los agustinos. Celebró la misa, su comendador Marcos González. Tras el sermón que recuperaba la imagen de Juan Diego, el gremio de los aguadores, no obstante la imagen tradicional de pobreza del indio, representó su coloquio con toda la suntuosidad en sus vestidos y ornamentos confeccionados con abundante pedrería, llamando la atención a lo que el relator nombra como alhajas indianas: "Bien pudiera morirse de sed esta tarde Zacatecas, que no había de hallar quién le trajese un cántaro de agua: bien que no fue necesaria, porque bastó la que se nos hacía en la boca, mirando la ternura de los Juan Diegos." ${ }^{44}$

El quinto día a las nueve de la mañana, ofició la misa el rector del colegio de la Compañía de Jesús, José de Ynsausti. La narración advierte que tras la expectativa de los habitantes de esta ciudad de que la Compañía no haría un buen papel en relación con las otras órdenes, se engañó, pues todo salió a la altura de la celebración. El gremio de los sastres hizo gala de su oficio, llevaba una carro adornado con plata, oro y cristales y era tal la tentación que "al llegar la noche fue providencia muy cuerda retirarlo para evitar contingencias." ${ }^{45}$ Dentro del carro, acompañaban la celebración ocho violines que alternaban con los pasajes de una loa.

El día sexto, ocho de septiembre, a más de la confirmación de Guadalupe como patrona universal de la Nueva España, la descripción recupera el motivo de la conquista refiriéndose como "la más

42 Ibid., p. 22.

43 Ibid., p. 24.

44. Ibid., p. 28.

45 Ibid., p. 31. 
dichosa época de su felicidad en que las armas españolas, ayudadas del Patrocinio de María, sujetaron a los guerreros indios chichimecas que dominaban esta provincia, comenzando desde entonces a rayar en ella la más apacible aurora, en los crepúsculos de la fe. ${ }^{\prime 46}$ El discurso justifica abiertamente la conquista, señalando que no sólo los españoles portan sus armas, sino la luz verdadera que viene a iluminar a estos bárbaros chichimecas. Insiste en que con la conquista se inicia la nueva nación. Como era costumbre vieja, el cabildo, para celebrar este acontecimiento, sacaba el real pendón por las principales calles de la ciudad en manos del alférez; en1758 Juan de Rábago fue designado por el cabildo como portador del pendón, acompañado de "sujetos de distinción", quienes cabalgaban sobre hermosos caballos. El estandarte fue colocado en el templo. Los cultos siguieron y en boca del panegirista Miguel de Espinosa, del convento de san Agustín, se recordaron las dos solemnidades: la natividad de María y la conquista de Zacatecas.

A estos días siguió la procesión en donde las mujeres se pusieron a vestir santos, a adornarlos con sus propios ajuares para dar gracias a Dios. Para ello, la competencia entre las mujeres zacatecanas se dio para ver cuál era la que vestía al santo con más hermosos trajes y piedras: "no faltó quien llorase pensando que se quedaba atrás, exclamando Pobre de mi santo, pero no tuvo razón." ${ }^{47}$ Las campanas sirvieron de signo para dar la bienvenida en la parroquia a los santos que los traían desde las casas de sus respectivas recamareras. La plaza fue llenándose de gente y entre los resquicios de puertas y balcones, se asomaban imágenes de la Virgen de Guadalupe. Fueron 66 los altares que se colocaron en esta fiesta para honrar a la Madre de los mexicanos.

La fiesta y su sonoridad como productora de estruendos simbólicos, mezclaba clarines y cajas, cohetes y ruedas, exclamaciones

46 Ibid., p. 32.

47 Ibid., p. 35. 
de la gente en una "confusión devota" que reclamaba también la presencia de los naturales con sus recitaciones. Éstos, vestidos a la "usanza de sus mitotes o saraos" y cargando los estandartes que identificaban a cada pueblo, danzaban entre tambores y violines. Los diferentes grupos siguieron la ruta de la procesión: la ilustre religión de San Juan de Dios y su Santo Patriarca; la religiosísima familia del Real y Militar Orden de Nuestra Señora de las Mercedes; después venía, representando el águila del Apocalipsis, el señor San Agustín "batiendo dos garbosas alas", presidiendo a los cuatro doctores: Santo Tomás, San Buenaventura, San Agustín y el Padre Suárez, "los que tomando de sus alas las plumas han formado cañones para desbaratar los monstruos de la herejía y sujetar aquella hidra que de tiempo en tiempo iba sacando nueva cabeza." ${ }^{48}$ Detrás venía, sin tocar riquezas, el humilde San Francisco que, no obstante su pobreza, fue parte distinguida en este aparato de grandeza; le seguía el patriarca Santo Domingo que, en oposición al anterior, vestía una riquísima capa y capilla de terciopelo. Después de un intervalo, llegaba el venerable clero y la congregación de San Pedro: el Santo venía cargado en hombros "ostentando de esta suerte ser la Suprema Cabeza de la iglesia universal."49 Parecía San Pedro confirmar el patronato de Guadalupe. La imagen que cerraba la procesión era la de Madre María Santísima de Guadalupe en lienzo. A pesar de tratarse de un lienzo, también fue adornado y causó asombro entre la gente. "Era conducida en hombros de sacerdotes, como aquella misteriosa arca de Israel, y a su vista se paraban reverentes las olas del pueblo." ${ }^{50}$ Presidían los señores comisarios José Joaristi y Francisco Javier de Aristoarena y Lanz. No podemos dejar de mencionar la importancia simbólica del lugar que ocuparon en la procesión estos comisarios, no sólo por

48 Ibid., p. 39.

49 Ibid., p. 42.

50 Ibid., p. 43. 
organizar la función, sino porque se viera quién estaba cerca de Guadalupe, pero no la Preladita, sino el lienzo motivo de pugna. Así iban estos comisarios, cerca de su Madre, en medio de una ciudad y sociedad que les debían sus preeminencias y honores. Así iban, cerca de Guadalupe con sus cetros de plata en la mano, sirviendo de costados al nuevo estandarte que orlaba el título de $\mathrm{Pa}$ trona con las Armas de esta Muy Noble y Leal Ciudad de Zacatecas. Atrás de los comisarios y a espaldas del lienzo, el muy ilustre cabildo, presidido -en ausencia del corregidor Vicente de Obeso y Rábago- por su teniente general José Martínez de Bustamante.

En este contexto festivo se mezclan y caminan por las calles el poder de la iglesia y el poder del ayuntamiento, en donde las intenciones políticas y religiosas se confunden, en donde la escena del sermón queda como un elemento más que cobra sentido desde su propia cultura: como un ritual que obedece a ciertas prácticas institucionalizadas por la tradición.

Los sermones que nos ocupan fueron pronunciados en la iglesia parroquial mayor de Zacatecas. Bajo este tipo de ceremonial, los predicadores anunciaban la palabra de Dios, la interpretaban, la adecuaban según la experiencia del motivo a celebrar, la proclamaban a un auditorio que esperaba ansioso el sermón. Pero en este contexto, es preciso volver a señalar que no es más un auditorio abstracto, es un auditorio que buscaba intenciones políticas; quería escuchar de los predicadores su propia afirmación como grupo social; quería escuchar lo que ellos mismos sabían, pero no podían decirlo con artificio. Joaristi y Aristoarena fueron quienes invitaron a los predicadores para celebrar este motivo de renovación. Los sermones fueron no sólo mandados pedir, fueron pagados, escuchados en donde todos estaban sentados como ordenaba la tradición. José Joaristi y Francisco Javier Aristoarena estaban ahí como hijos piadosos en la banca del cabildo, buscando merecer el honor que el cabildo les había conferido al nombrarlos comisarios. Todo estaba en su lugar: los conflictos latentes con los franciscanos no fue- 
ron motivo para que esto se suspendiera; más bien fueron un pretexto para mostrar nuevamente quién es quién; mostrarse ante los otros como los hijos de Guadalupe cargando un lienzo y colocándolo en la iglesia parroquial mayor de Zacatecas. El problema con los franciscanos fue un problema que aprovecharon los miembros del cabildo para asegurar ahora quiénes tenían poder de convocar a una sociedad para rendir culto. No podemos con ello decir que los franciscanos no hubiesen tenido ese poder de convocar y reunir; su participación como misión evangélica durante el siglo XVII dio muestras amplias de su capacidad de convocatoria. Pero ahora se trataba de establecer una lucha entre dos que convocan: entre los que se dicen hijos de la Santísima Guadalupe e hijos del cabildo metropolitano y los que se dicen promotores de la verdadera devoción del pueblo por Guadalupe. Esto es, los que se encargan de que públicamente se muestre su guadalupanismo y los que bajo su fortaleza -como lo señala la descripción- le rinden culto de manera privada. La lucha por el culto guadalupano en Zacatecas ofrece una excelente aproximación a una sociedad que justo en las apariencias mostraba sus contradicciones: se cargaba un lienzo mandado hacer a México, desairando a la propia Preladita que guardaban celosamente los franciscanos. Sin embargo, la Preladita era el objeto sagrado que la tradición veneraba, era el objeto de devoción del "pueblo". Ahora, el pueblo veía a Guadalupe en otro modo de representación plástica, ajena a la pequeña imagen. Atrás de la lucha de las imágenes, la lucha de la preeminencia como imagen simbólica del poder, un poder que se daba el lujo de enfrentarse a la tradición misionera franciscana y al mismo tiempo de invitarlos a participar en su fiesta dedicada a Guadalupe.

Es difícil contar con documentos que hagan referencia a la recepción que tuvieron los sermones entre los oyentes; sin embargo, hay algunos indicios que nos permiten imaginar ciertos elementos de esta recepción. En el impreso que nos ocupa, se menciona que después de pronunciado el sermón se aclamaba y por ahí alguien decía: 
Vive diola, que el Doctor, predicó tan elocuente; que quedará malamente si lo hubiera hecho mejor.

Porque a su prosa, sólo le hacía falta

lo que le sobra. ${ }^{51}$

El impreso recupera opiniones de letrados que afirmaban después de escuchado el sermón:

Que dijese mil primores

el orador de este día,

no es mucho si se escogía

de entre los Predicadores.

Ni es cosa nueva

que todos le escucharan

la boca abierta. ${ }^{52}$

La competencia entre los predicadores es percibida por alguien del auditorio, pues se se van dando muestras de quién predicó mejor, de quién se esperaba más, quién conquistó el eco, quién cumplió satisfactoriamente con las expectativas generadas, de tal manera que después de escuchado el sexto sermón, alguien anotó:

Todos con igual primor

celebraron los loores

de Marla, pero Señor,

entre los predicadores

sólo el de hoy es superior. ${ }^{53}$

Estos versos que se encuentran en el impreso permiten suponer la eficacia del predicador para conmover voluntades, persuadir conciencias, reconocer que la palabra es una acción que tiende al movimiento y que es parte de un movimiento cultural. Los recursos del orador son su voz, su intensidad, sus gestos, el movimiento de

51 Ibid., p. 14.

52 Ibid., p. 18.

53 Ibid., p. 33. 
su cuerpo, para hacer de él un instrumento más que logre dramatizar lo dicho. El púlpito ofrece un lugar privilegiado, en lo alto, como en el monte, como la tribuna para ser visto y reconocido por todos, para que su voz sea oída en esta acústica que de por sí le favorece. Según José Andrés-Gallego, quien se refiere a la "patética sermonaria", señala que el predicador barroco se vale a menudo de artificios de carácter claramente teatral para poder ofrecer una imagen tortuosa y elocuente de lo que dice. Es ilustrativo el ejemplo que ofrece sobre la manera en que Diego de Arce, en España, representó la imagen de la sífilis para persuadir a su auditorio:

Una tristeza de rostro, una amarillez de cara, un gangosear de narices, un hediondo anhélito de boca, un descarnamiento y sangraza de dientes, un dolor de todos los miembros, un humor que atormenta las coyunturas, un no andar, ni sentarse $\sin a y$, y finalmente, un semblante asqueroso de toda la persona. ${ }^{5 . t}$

Los sermones de 1758 fueron justo lo contrario a este caso, empero no se sacrificó el drama ni la capacidad de representar de los predicadores. Fue una fiesta que se prolongó dos semanas, en la primera fue notoria la participación del clero regular y secular y en la segunda, la sociedad celebraba con toros, cohetes y bebidas lo que se había reiterado durante los seis primeros días en el púlpito.

Si pensamos, desde la propuesta antropológica de Clifford Geertz, que la cultura es esa red de signos que el mismo hombre ha tejido para producir significados que lo identifican, que lo nombran, esto nos permite pensar en que la categoría de texto para pensar un mundo cultural, necesariamente tiene que abrirse. Hay muchos nudos que siguen sin interpretarse. La maraña de textos que se tejieron en este pequeño contexto ofrece signos irrenunciables para la interpretación. En estos púlpitos novohispanos en que se pronunciaron infinidad de sermones elaborados por predicadores que buscaron nombrar a Dios de muchas posibles maneras, no se puede

54 José Andrés-Gallego y Manuel Morán, "El predicador", El hombre barroco, Madrid, Alianza, pp. 174-175. 
establecer con tajante determinación en dónde empieza y termina el texto; en dónde termina lo oral y comienza lo escrito, o hasta dónde podemos hablar de que la tradición sermonaria colonial en Zacatecas es fundamentalmente escrita o fundamentalmente oral; hasta dónde un impreso y su sentido es favorecido también por los gestos del predicador para impresionar y conmover o hasta dónde se carga de sentido por quienes lo mandaron pedir y acudieron solemnes a escucharlo. La cultura de lo escrito no es privativa de quienes saben leer y escribir; la cultura de lo escrito es comunicada y apropiada también por los analfabetas que escuchan e interpretan y por las élites que saben firmar y saben de los canales para financiar un impreso. Lo escrito, por tanto, no se queda en la lectura individual y silenciosa, no por lo menos en esta circunstancia. Esto puede leerse en los sermones en cuestión y en el ritual festivo del que forman parte. La cultura sermonaria vista a través de este impreso de la descripción y los seis sermones, puede leerse como un nudo que es atado no sólo por los predicadores y los censores, sino también por las redes económicas y políticas de Zacatecas hacia el siglo XVIII que buscaban tras la imagen, una imagen de sí mismos. La descripción de la fiesta ofrece un todo armónico en donde la procesión está estructurada, los últimos serán los primeros y no quiero decir con ello que Zacatecas fue de las últimas ciudades en celebrar la confirmación, sino que los últimos que van en la procesión serán los primeros, los que estén más cerca de Dios y más lejos del demonio. Como señala Roger Chartier: "la fiesta que jerarquiza, a la vez que une..." ${ }^{95}$

Finalmente, debemos señalar que todo este contexto con su producción de textos diversos, fue un evento extraordinario en Zacatecas, pero que, a pesar de estar tan lejos de lo ordinario, o precisamente por eso, ayuda a explicarlo.

55 Roger Chartier, Sociedad y escritura en la época moderna, México, Instituto de Investigaciones José María Luis Mora, 1995, p. 10. 